\title{
Materiality and Agency in Improvisation: Andrea Neumann's "Inside Piano"
}

\section{Matthias Haenisch ${ }^{1}$}

Pushing the boundary of material and continually innovating instrumental techniques are part of the history of jazz, and can be found in an even more radical form in the improvising avant-gardes of the 1960s and 70s. ${ }^{2}$ The branch of improvised music that broke away from the jazz tradition was influenced by, among other things, the aesthetics of John Cage, which inspired far-reaching experiments involving instruments and material. ${ }^{3}$ In this way the emancipation of noise also left its mark on improvisation, opening up new paths for the exploration of material, and it has had a formidable and lasting impact on performance practice in the field. The extension of musical material accompanied a correspondingly wider understanding of what can be considered an instrument, because, as a consequence of the leveling of the hierarchy between noise and music, "the need for a line between what is and what is not a musical instrument was firmly broken." ${ }^{4}$ The resulting proliferation of musical objects and practices runs the gamut from extended instrumental techniques on traditional instruments, to the modification or dismantling of instruments, or even the construction of newly invented ones, to the innovative (mis) use of analog or digital recording and playback

1 Translated by Carter Williams.

2 Cf. Peter Niklas Wilson, Hear and Now. Gedanken zur improvisierten Musik (Hofheim: Wolke, 1999), 74.

3 Nina Polaschegg, "Reflexive Improvisation? Fortsetzung, Reflexion, Korrektur der 'Moderne' in der jüngsten 'frei' improvisierten Musik," in Orientierungen. Wege im Pluralismus der Gegenwartsmusik, ed. Jörn Peter Hieckel (Mainz, London, New York: Schott, 2007), 224.

4 Andy Keep, "Instrumentalizing: Approaches to Improvising with Sounding Objects in Experimental Music," in The Ashgate Research Companion to Experimental Music, ed. James Saunders (Farnham: Ashgate, 2009), 116. 
equipment and the appropriation of found objects and industrial artifacts as sound sources. Many of these practices are unorthodox, manipulative, or deconstructive, and carry out "creative abuse" ${ }^{5}$ on the existing world of things. With respect to musical material, the instrument is no longer a readymade, general-purpose object. On the contrary, the instrument only emerges through a process of "instrumentalizing" that aims to unleash the hidden musical qualities of virtually every object. This necessitates a paradigm shift in our concept of an instrument from a predetermined object to a performative act: $^{7}$ a fork, a clothespin or an electric fan only become instruments once they are integrated into a musician's performance practice. As improvisers strive to expand their individual sound repertoire, their unique, often homemade, and reconfigurable instrumentarium grows. The knowledge of the practitioner, her appetite for exploration, her aesthetic stance, and sometimes the implicit rules of her performance practice all begin to materialize in the process of constructing such an assemblage.

Andrea Neumann's "Inside Piano" is a representative product of this development. The instrument's construction and configuration bring together a multitude of instrumentalizing practices: the deconstruction of the musical instrument, the partial integration of other musical instruments such as violin bows and guitar pickups, the musicalization of everyday objects such as potato mashers and shaving brushes, and the creative (mis)use of audio equipment, for example using a mixing board as a sound source (Figure 1).

In this chapter I explore questions regarding the specific function and role of the instrument and the objects in Andrea Neumann's work. ${ }^{8}$ I will

5 Keep, “Instrumentalizing,” 116.

6 Keep, "Instrumentalizing," 113.

7 Keep, "Instrumentalizing," 113

8 My investigation is based on Neumann's published and unpublished texts, as well as interviews and video recordings made over the course of a research project into performance practice in improvised music that has been in progress since 2011. 


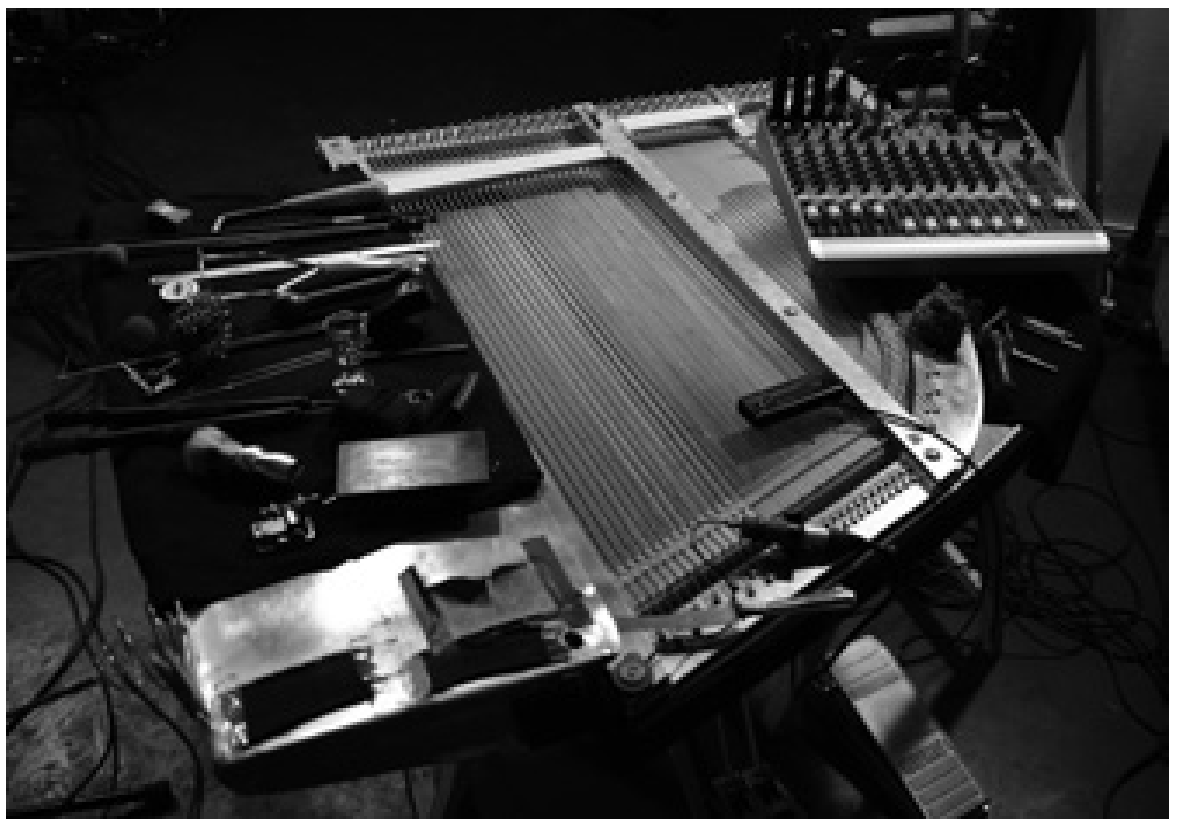

Figure 1: The Inside Piano overview (photograph by Manuela Stark)

attempt to show that the artifacts of the practice are at the same time among its actors; that is, they are performative participants in the improvisation. The significance of this observation is that it prompts the integration of natural and technological objects into the analysis of performative processes. Along these lines I would like to position myself squarely among those who question the widely held view that instruments are simply a tool, prosthesis, or extension of the musician. ${ }^{9}$ In order to be able to observe the active role that things play in improvisation practice, I refer throughout the text to

9 Cf. David Borgo and Jeff Kaiser, "Configurin(g) KaiBorg: Interactivity, ideology, and agency in electro-acoustic improvised music," Beyond the Centres: Musical Avant-Gardes Since 1950: Proceedings, ed. C. Tsougras, D. Stefanou, and K. Chardas (2010), last accessed August 2, 2013, http://btc.web.auth. gr/_assets/_papers/BORGO-KAISER.pdf; Franziska Schroeder, "The voice as transcursive inscriber: The relation of body and instrument understood through the workings of a machine," Contemporary Music Review 25/1-2 (2006): 131-38. 
several assumptions from Actor-Network Theory (ANT), which has its origin in the 1980s and was principally developed by Bruno Latour, John Law, and Michel Callon. ${ }^{10} \mathrm{~A}$ central conceit of this theory is to examine the way objects, things, and technologies participate in social processes. In order impartially to determine the social meaning and function of things, ANT takes the generalized symmetry of human and non-human actors as a starting point. Within the framework of this theory any entity that is able to affect some sort of change is termed an actor (or actant). These can include people, animals, material objects, technical artifacts, concepts, and discourses. These entities become actors when they link to other actors to form networks. The emergence of such heterogeneous networks is a transformational process, in which the properties and activities of all human and non-human actors are equally involved and at the same time changed. By joining a heterogeneous network, human and non-human actors modify one another reciprocally. User and artifacts do not remain as they were before; they become something else. Such a network can therefore itself be seen and described as a new collective actor-a hybrid actor. ${ }^{11}$ Against this background I would like to try to expose various aspects of the collaboration between human and nonhuman in Neumann's performance practice. ${ }^{12}$

10 Bruno Latour, Reassembling the Social: An Introduction to Actor-Network-Theory (Oxford: Oxford University Press, 2005); John Law, "Notes on the Theory of the Actor-Network: Ordering, Strategy, and Heterogeneity," Systems Practice 4/5 (1992): 379-93; Michel Callon, "Some elements of a sociology of translation: domestication of the scallops and the fishermen of St Brieuc Bay," in Power, action and belief: a new sociology of knowledge?, ed. John Law (London: Routledge, 1986), 196-223.

11 Bruno Latour, "On Technical Mediation-Philosophy, Sociology, Genealogy," Common Knowledge 3/2 (1994): 29-64; cf. Michel Callon, "Society in the Making. The Study of Technology as a Tool for Sociological Analysis," in The Social Construction of Technological Systems: New Directions in the Sociology and History of Technology, ed. Wiebe E. Bijker et al. (Cambridge: MIT Press, 1987), 93: "[The actornetwork] is simultaneously an actor whose activity is networking heterogeneous elements and a network that is able to redefine and transform what it is made of."

12 Cf. Borgo and Kaiser, "Configurin(g)," 4: "If we tentatively define electro-acoustic improvised music as real-time musicking involving humans, acoustic sound sources and spaces, and interfaces with electronics, then the practice appears to foreground (perhaps in somewhat equal measure) issues of human-human, human-machine and human-text (e.g., a computer program, or the 'media message' of performance) interactivity." 


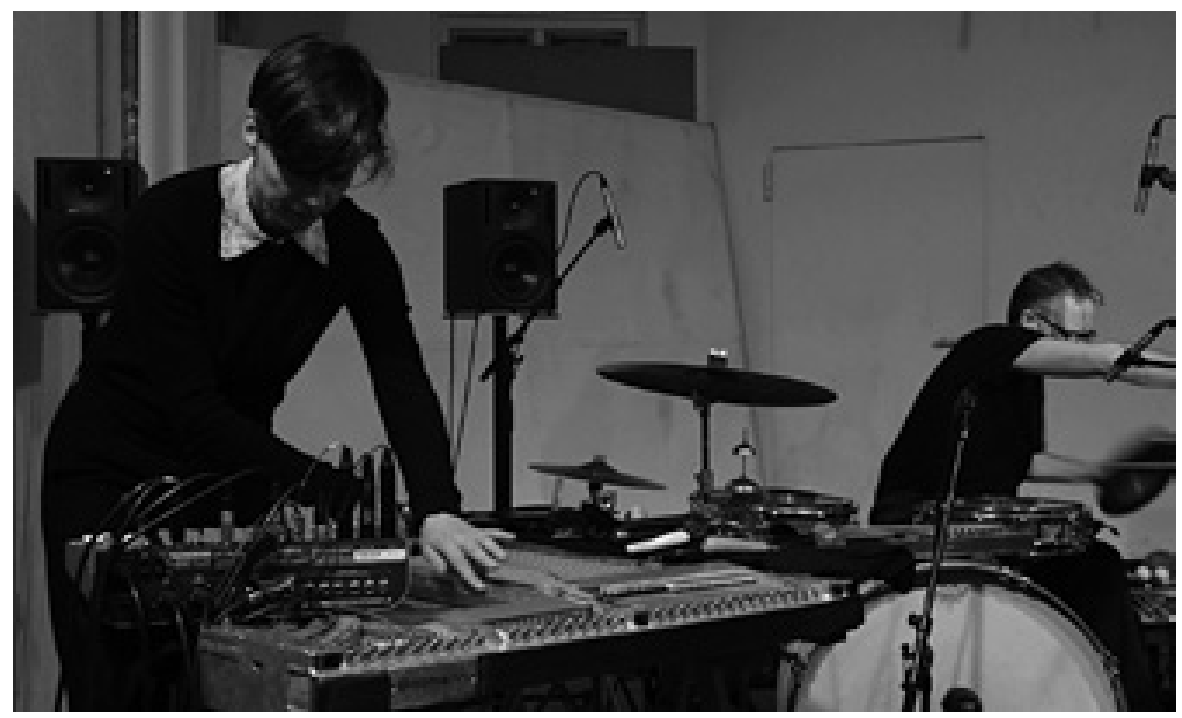

Figure 2: Andrea Neumann, Inside Piano (Background: Burkhard Beins, percussion, objects; not pictured: Valerio Tricoli, reel-to-reel tape recorder). Concert at KuLe, Berlin-Mitte, March 26, 2013 (still from video by Norbert Artner)

As was the case with many improvisers, Cage's work with the prepared piano was an important point of departure for Neumann in the search for new sounds "that convey a shorter history than that of a sound made by a pressed key." ${ }^{13}$ However, in marked contrast to the now widespread practice of preparation and playing inside the piano, Neumann's instrument is one-of-a-kind. In its current form, it is made up of three playing areas: the "actual" Inside Piano consisting of an aluminum replica of a piano harp, an aluminum shelf for objects and preparations, and a mixer that is used for sound processing, mixing, and as a sound source. Neumann's recombination and continual further development of playing techniques and instrumental concepts from 20th-century and contemporary music history can be clearly

13 Andrea Neumann, "Playing Inside Piano," in Echtzeitmusik: Self-defining a scene, ed. Burkhard Beins et al. (Hofheim: Wolke, 2011), 203. 
seen. These include exploiting and preparing the inside of the piano, techniques that first appeared in new music (Henry Cowell, John Cage) and then later in the collective improvisation of the 1960s (Nuova Consonanza); the use of everyday objects to generate sounds (Cage); idiosyncratic combinations of objects such as steel coils or electric fans with guitar pickups (Keith Rowe); and using the so-called no-input-mixer as a sound source (Toshinori Nakamura), a use which Richards has characterized as "bastardization." ${ }^{14}$ In addition there are a number of original playing techniques that have originated on this instrument. Neumann began the development of the Inside Piano around 1995 at the same time that she started to emerge as a fixture in Berlin's Echtzeitmusik ("real-time music") scene. The instrument has not only been closely linked to Neumann's development as a professional improviser from the very beginning, but is also interwoven into the sociological fabric and aesthetic disposition of a scene of improvised and experimental music that came together in Berlin after the fall of the Berlin Wall. The development of the Inside Piano did not follow any a priori plan. ${ }^{15}$ Rather, the instrument arose out of years of negotiation, communication, and interaction, which in the context of ANT can be termed a "translation," a process of building a network in the course of which the identities, capabilities, roles, and functions of human and non-human actors are redefined, displaced, and transformed in order to align them to a collective program of action. ${ }^{16}$

Initially it was economical limitations and their technical solutions that led to significant aesthetic developments. ${ }^{17}$ Most of the venues in the free concert scene in Berlin at the time were underground, makeshift, and

14 John Richards, "32kg: Performance Systems for a Post-Digital Age," Proceedings of the New Interfaces for Musical Expression Conference, Paris (2006): 284.

15 Andrea Neumann, "Development of the Inside Piano" (Berlin: unpublished, 2008), 1.

16 Callon, "Sociology of translation," 196.

17 Neumann, "Development," 1. 
repurposed spaces that as a rule did not have a piano. ${ }^{18}$ Therefore Neumann had to come up with a transportable instrument just to be able to perform. Inspired by Zeena Parkins' prepared harp-both with regard to the lighter construction as well as the sonic possibilities-Neumann decided to do without the keyboard and the body of the piano and to work with just the naked plate, including strings and soundboard, from an original piano frame provided by the piano maker Bernd Bittman. But this now transportable instrument also brought certain limitations. Initially the cast iron frame was placed upright and leaned against a wall, making it extremely difficult to attach preparations to the instrument. Neumann sat on the floor wearing wool socks so that she could damp the strings with her feet. Later the instrument was placed on wooden blocks, and because it was not loud enough for certain performance situations, it was fitted with a guitar amplifier. In 2000, following Neumann's request, Bittmann, who had by that time already procured two original piano frames for Neumann, built a custom replica of a piano harp made of aluminum that was much lighter. This new instrument, which was designed above all to make transport easier, was also fitted with a pedal mechanism, which had been missing up until this point, as well as a shelf to hold preparations. However, due to the lighter construction the sound of the instrument was much weaker, which necessitated the installation of an optimized amplification system with an array of piezoelectric contact microphones and a mixer. This meant that the instrument's timbre became further removed from the "original" Inside Piano. On the other hand, the use of contact microphones led to intensified experimentation with subtle sounds and noises under the magnifying glass of extreme amplification.

Likewise, the mixer could be used as an additional sound generator and allowed for the simultaneous processing of parallel layers of sound as well as blending acoustic and electronic elements. Thus the continuous and often

18 Dietrich Eichmann, “Orte, Musiker, Ästhetiken. Die Berliner Szene," positionen. Texte zur aktuellen Musik 62 (2005): 22. 


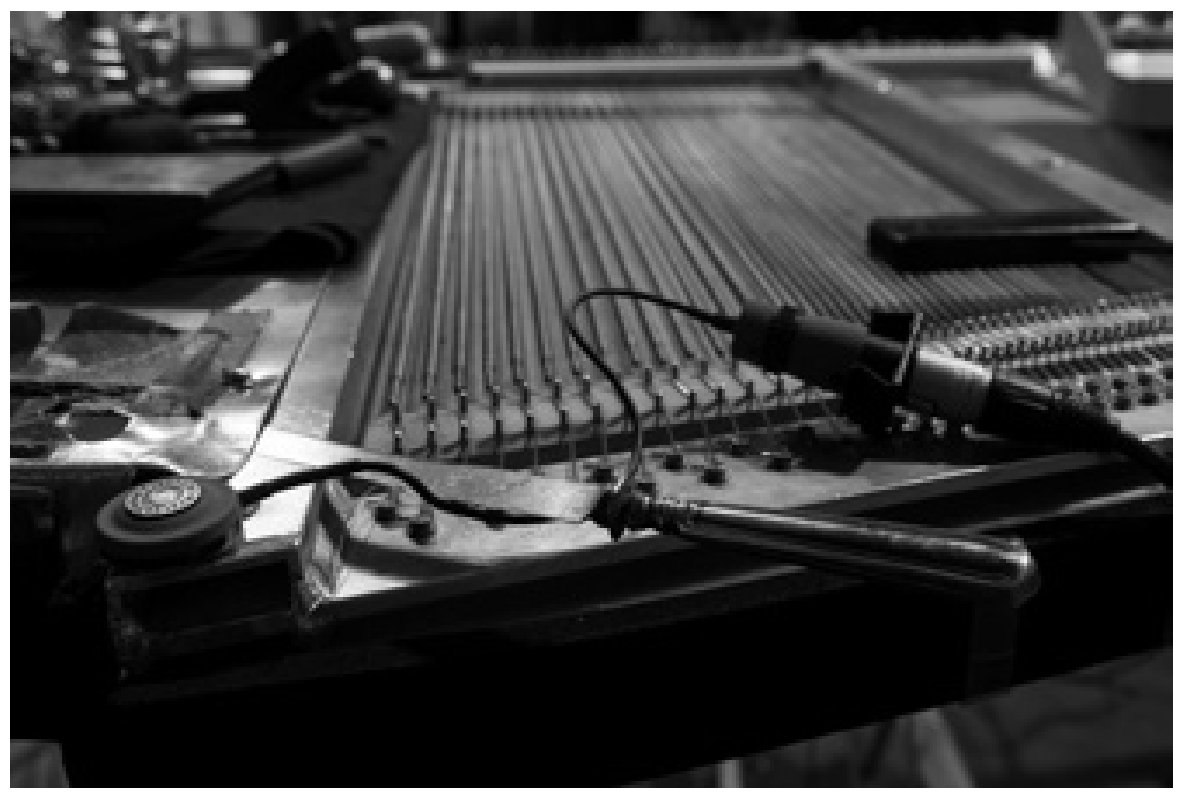

Figure 3: Contact microphone, knife, guitar pickup (photo by Norbert Artner)

pragmatic reconfiguration of the instrument paved the way for new and surprising possibilities to shape sound, with a marked effect on Neumann's musical bearing. The contact with an ever expanding number of objects and preparations gave rise to an inner soundworld connected to specific materials. And with the increasing awareness of materials, musical concepts, and new artistic goals began to crystallize, which Neumann then in turn transferred to further reconfigurations, new objects, and different preparations. Performer and artifacts found themselves entwined in a reciprocal process of perpetual transformation. ${ }^{19}$ Through this process-over years of translation between the demands of performance practice, monetary constraints, craftsmanship,

19 Similar to Pickering's description of scientific instrument development, the development of the Inside Piano reveals itself as a dance of agency, "a performative, transformative and productive back and forth between human and non-human agency," see Andrew Pickering, "Ontological Politics: Realism and Agency in Science, Technology and Art," Insights 4/9 (2011): 3. 
technological adaptations, instrumental reconfigurations, experimental preparations, aesthetic decisions and artistic impulses in a network of collaborating agents - work with amplified small sounds, probing the depths of the noise worlds in the gray area between acoustic and electronic, grew to become a characteristic feature of Neumann's personal style. The genesis of such a personal style would remain inscrutable against the backdrop of a dualistic view between an autonomous and intentionally acting subject and a determined object. Instead, performer and instrumentarium have become what they are through a "mutually constitutive process through which users, technologies, and environments are dynamically engaged in refashioning one another in a feedback loop." ${ }^{20}$ In the course of this mutual configuration of performer and instrument, a hybrid actor has emerged whose aesthetic agenda is no longer reducible to the individual programs of action of the human and non-human actors who make up the network.

In the following account, Neumann gives a detailed insight into the relationship between performer and artifact, in which it becomes apparent how the materiality of objects, the construction of the instrument, physical abilities, practical knowledge, and musical imagination are equally involved in shaping the soundworld and developing a specific instrumental technique:

A small bamboo rod (for the stabilization of plants), for example, has a particular radius. One must ascertain which strings the stick can be held between with relative firmness so that it stays put when rubbed. This procedure (with undampened strings and pine resin on one's fingers) leads to a voice-like sound. If there are places on the rod where the bamboo's skin is loose, then one must find out at which tempo and with which pressure this place should be brushed so that it makes a good sound. The

20 Borgo and Kaiser, “Configurin(g)," 2. 


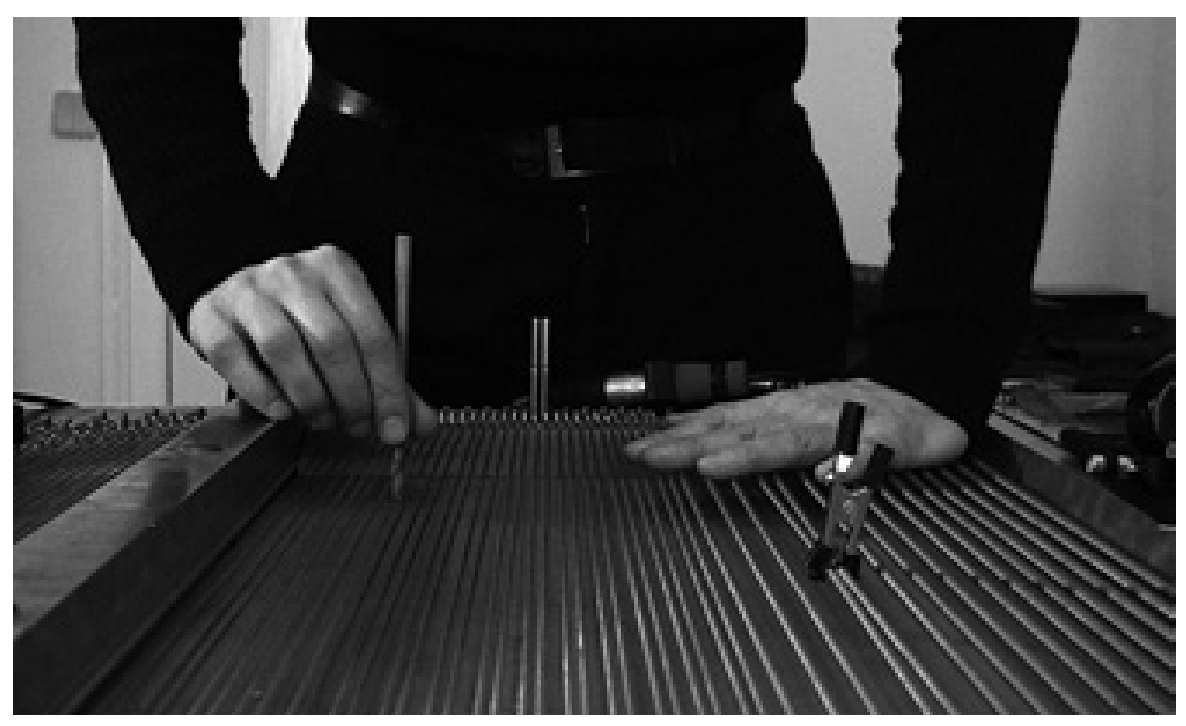

Figure 4: Neumann playing the bamboo rod (still from video by Matthias Haenisch)

damaged place can end up becoming the special quality of the preparation, since, for example, the air underneath the loose bamboo skin has an effect on the sound's pitch. ${ }^{21}$

Here we can clearly reconstruct the process of transformation and translation of disparate trajectories of individual entities into the program of action of the performer-instrument network. In an initially experimental setting, a bamboo rod is wedged between the strings in a manner similar to Cage's use of screws and nails. An attempt is made to coax a sound out of the bamboo rod, contrary to its purpose as a gardening tool, by rubbing it with a finger. Another artifact, violin rosin, also contrary to its intended use, is incorporated into the network so that the bamboo can be brought into a greater resonance through a stick-slip effect. The artifacts involved enable or hinder certain actions, demanding physical and technological adaptation

21 Neumann, “Playing Inside Piano," 207. 
to their material nature and resistance. Slight variations in the position of the bamboo and differences in finger pressure and moisture lead to changes in the sound. ${ }^{22}$ The materiality of body and artifacts enter into reciprocal coupling. At the end of this chain of operations a damaged spot on the bamboo rod serendipitously appears as an important factor in creating a truly original sound neither intended nor foreseen. Sound and playing technique cannot be traced back to an antecedent intention; rather they are a result of a contingent transformation of physical abilities, botanical secretions, historical references, horticultural intentions, mental states, material damage, and so on into an ephemeral network unified by a new goal. This process of interaction described by Neumann demonstrates the performative genesis of a characteristic sound and a particular playing technique as an emergent effect of a heterogeneous association between human and non-human actors.

Building on the work of Schroeder and Rebelo on the performer-instrument relationship, I understand this process of performative instrumentalization not to be a form of control but instead as creating an open and participatory environment ${ }^{23}$ "in which the instrument or the device itself suggest specific ideas of their textures and in which the human body becomes acquainted with the 'thing' at hand by being able to test boundaries, negotiate subtleties and uncover certain threshold conditions." ${ }^{24}$ This gives rise to a relationship between performer and object that can be described more specifically with the help of one of the central concepts of ANT, affordance. ${ }^{25}$ Affordances

22 Neumann, "Playing Inside Piano," 207.

23 Cf. Pedro Rebelo, "Haptic sensation and instrumental transgression," Contemporary Music Review 25/1-2 (2006): 28.

24 Franziska Schroeder, "Caressing the Skin: Mobile Devices and Bodily Engagement," Proceedings of the 5th International Mobile Music Workshop Vienna 2008, accessed August 1, 2013, http://www. mobilemusicworkshop.org.

25 Bruno Latour, "Morality and Technology: The End of the Means," Theory, Culture \& Society 19 (2002): 247-60; James J. Gibson, The Ecological Approach to Visual Perception (London: Lawrence Erlbaum Associates, 1986); Donald A. Norman, The Design of Everyday Things (New York: Basic Books, 1988). 
are the particular performance characteristics offered by an object or an environment that permit or suggest certain uses while eschewing and hindering others. The twofold meaning of this concept is crucial. On the one hand there are invariant material and physical possibilities, obstacles, and efficacies that are inherent to the object of the bamboo rod. On the other hand possibilities for using the object only exist with respect to trained physical and mental skills, schemes of perception, expectations, and attitudes of the subject. Affordances are relationships of mutual dependency that subvert a clear subject-object dichotomy because they only become real in and through interaction. They reveal the relationship between materiality and corporeality to be one of performative productivity. ${ }^{26}$ However, things, artifacts, and even natural objects are by no means passive matter that is only defined and shaped by practice. On the contrary the materiality of things, as an "agent of transformative efficacy," ${ }^{27}$ is always involved in creating and executing a practice. ${ }^{28}$

The concept of affordance refers not only to the transformative efficacy of the artifact but also the attitude with which Neumann confronts her objects. It also alludes to the meaning of the aesthetic criteria according to which Neumann chooses certain objects and preparations while rejecting others. As became clear in an interview I conducted with Neumann, she was guided in her research into the Inside Piano by criteria she developed in ongoing

26 R. Schmidt, Soziologie der Praktiken. Konzeptionelle Studien und empirische Analysen (Frankfurt/Main: Suhrkamp, 2012), 67.

27 Ingo Schulz-Schaeffer, "Technik in heterogenen Assoziationen. Vier Konzeptionen der gesellschaftluchen Wirksamkeit von Technik in Bruno Latours Werks," in Bruno Latours Kollektive. Kontroversen zur Entgrenzung des Sozialen, ed. Georg Kneer et al. (Frankfurt/Main: Suhrkamp, 2008), 110.

28 I am referring here to Barad's "posthumanist notion of performativity—one that incorporates important material and discursive, social and scientific, human and nonhuman, and natural and cultural factors." See Karen Barad, "Posthumanist Performativity: Toward an Understanding of How Matter Comes to Matter," Signs: Journal of Women in Culture and Society 28/3 (2003): 808. Cf. Mathias Maschat, "Performativität und zeitgenössische Improvisation," kunsttexte.de/auditive_perspektiven 2 (2012), 10, www.kunsttexte.de. While contemplating the performative genesis of musical material, Maschat seems to miss or deny the performativitiy and agency of the material. 
cooperation with other musicians as one of the central figures of the Berlin scene. ${ }^{29}$ This means that in addition to individual preferences, the aesthetic disposition-what Bourdieu would call the artistic babitus - of an entire community of practice was caught up in the construction of the instrument. Since the mid-1990s, Neumann has belonged to a circle of musicians within the Echtzeitmusik scene who saw the energy, gesture, and expressivity of contemporary free improvisation as becoming exhausted. The search for alternative concepts led to an investigation of the soundworlds of new music (e.g., John Cage, Morton Feldman, Giacinto Scelsi), the reduced performances styles of improvisation collectives of the 1960s (e.g., AMM, Gruppo di Improvvisazione Nuova Consonanza), and the post-digital aesthetics of contemporary electronica and electronic music. Toward the end of the 1990s, these influences coalesced into the so-called "Berlin Reductionism."

[This] manifested itself in a rather strict material selection, concentration on only some acoustic elements by eliminating the other, slowing down, reducing density of musical events, avoiding immediate reactions while improvising in a group, re-evaluating the relation between sound and silence, reducing dynamics range, all in order to be able to achieve more control and more focus on a chosen element. ${ }^{30}$

Due to the rejection of structural and formal relationships and because of the isolation of musical events, the singular manifestation of a sound or noise along with its materiality and corporeality became the basis of a radical aesthetics of presence. In this milieu the distinct and individual sound repertoires of the improvisers followed a collectively developed program of

29 Interview with Andrea Neumann, April 5, 2013; cf. Andrea Neumann, "Influences."

30 Marta Blažanović, "Berlin Reductionism-An Extreme Approach to Improvisation Developed in the Berlin Echtzeitmusik-Scene," Beyond the Centres: Musical Avant-Gardes Since 1950: Proceedings, ed. C. Tsougras, D. Stefanou, and K. Chardas (2010), last accessed August 2, 2013, http://btc.web.auth.gr/_ assets/_papers/BLAZANOVIC.pdf; cf. Polaschegg, "Reflexive Improvisation,” 226. 
materiality. The musicians "were building common sound territories with focus on relatively quiet noises." 31 They tried to find material that would be rather "non-expressive, non-organic, and non-human, more machinelike, objective, and noise-like" that would recall everyday sounds "like those of washing machines, toilets flushing, heating, ventilation, or construction work." ${ }^{2}$ The aesthetic principles of immersion, "zooming into the sound," 33 and "acoustic microscopy" 34 became the categories for the selection, exploration, and molding of sound-categories that were translated into the construction of the Inside Piano, its extensions, and its playing techniques.

The form of the instrument and its reduction to the inside of the piano already seem to be a material exemplification of the immersive focus characteristic of Neumann's performances. In a similar way this "broken" relic of an earlier tradition corresponds to an aesthetic of "damaged sound," which Gottstein has identified as a distinctive feature of the Berlin scene. ${ }^{35}$ While hardly suitable for playing melodic and harmonic structures, Neumann's rudimentary piano has been optimized for the production of a wide range of precisely articulated noises and sound textures. The aesthetic principle of acoustic microscopy finds its physical manifestation in the close positioning of contact microphones at various points on the instrument and the invasive amplification of the quietest sounds on the Inside Piano: minimal movement, steel wool sliding over a guitar pickup, scraping sandpaper with jazz brushes (Figure 5), or letting a whisk vibrate while attached to the aluminum shelf

31 Blažanović, "Berlin Reductionism.”

32 Andrea Neumann, "Statement," in Reduktion: zur Aktualität einer musikalischen Strategie, ed. Peter Niklas Wilson (Mainz: Schott, 2003), 129; cf. Marta Blažanović, "Berlin Reductionism," 4.

33 Gisela Nauck, "Im Klang arbeiten. Innovationen in der aktuellen Improvisationsszene," kunsttexte.de/ auditive_perspektiven 2 (2012), last accessed August 2,2013, http://edoc.hu-berlin.de/kunsttexte/2012-2/ nauck-gisela-3/PDF/nauck.pdf.

34 Björn Gottstein, “An Aesthetic of Refusal," in Ecbtzeitmusik: Self-defining a scene, ed. Burkhard Beins et al. (Hofheim: Wolke, 2011), 152.

35 Gottstein, "Aesthetic of Refusal," 152. 


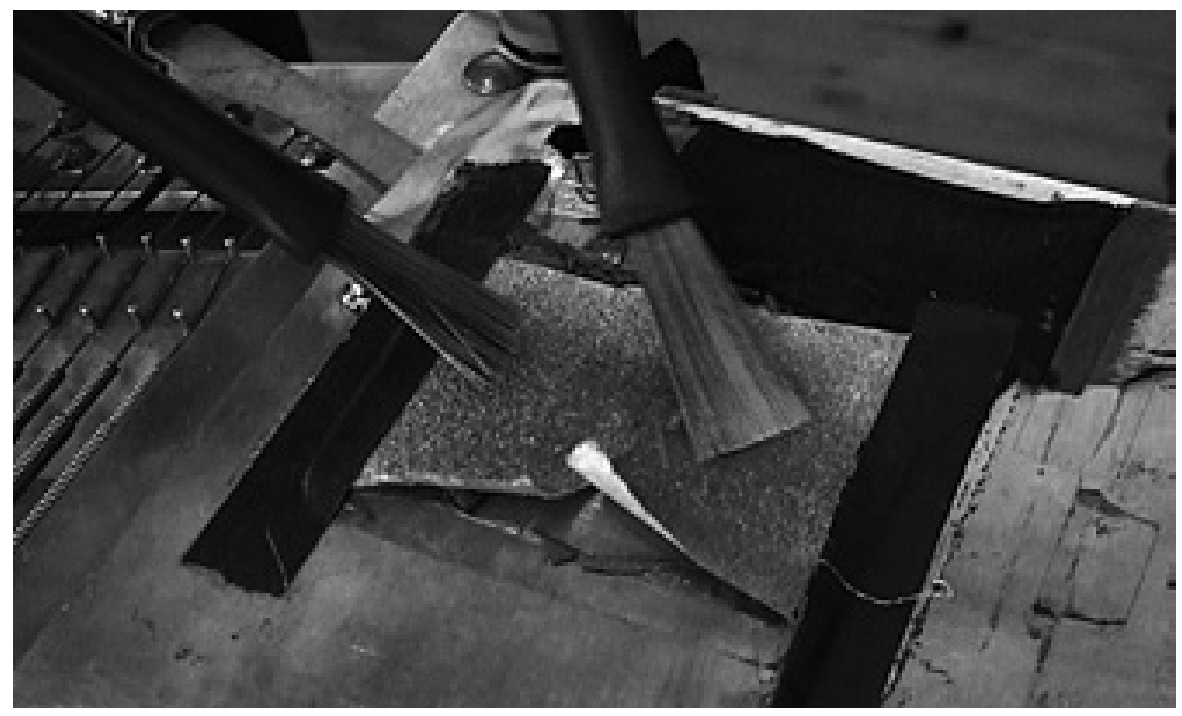

Figure 5: Jazz brushes on sandpaper (still from video by Matthias Haenisch)

all yield extremely heightened and, at the same time, somehow alien "interior views" of the sound.

The extreme diversity, internal articulation, and nuanced dynamics of many sounds generated on the Inside Piano are most effective in musical contexts where high density and volume has been abandoned in favor of absolute transparency and silence, which allows the presence of the sound to take center stage. The "bruitist" material aesthetic is represented by the multitude of objects that produce automatic, repetitive, and "mechanical" structures: hand-held electric fans, pulsating feedbacks, vibrating magnets, or oscillating knives, forks, etc. (Figure 6).

Many of these sound and object combinations came out of connections to the sound repertoire of a fellow musician:

The material that I work with can mostly be traced back to my experiences playing with other people. It is really the case that you are engaged in a 


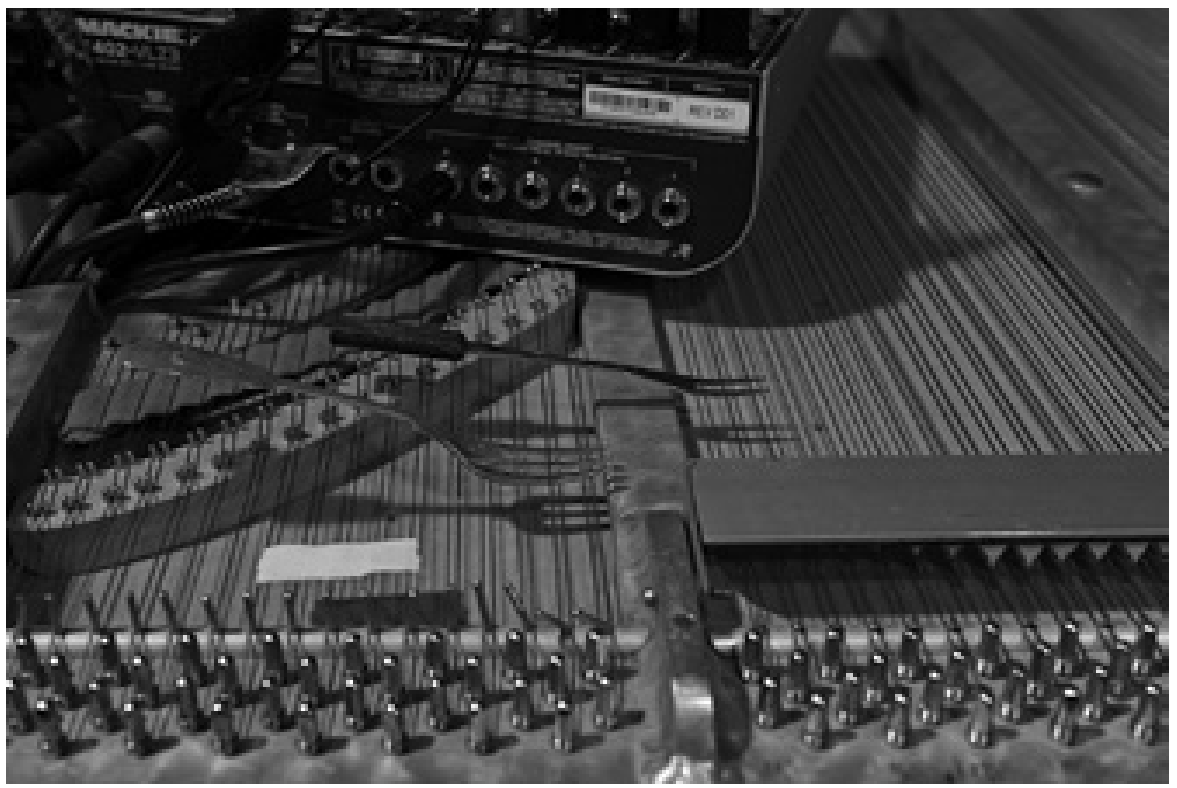

Figure 6: Forks (photo by Norbert Artner)

process of mutual influence. For example it often happens that in rehearsal or even while playing a gig you notice some particular sound and think that you would actually need a specific type of material in order to be able to react to that sound. And so you go looking for it. ${ }^{36}$

Certain sounds that found their way into Neumann's repertoire came out of her work with the ensemble Phosphor around 2000. A "fan-belt-like" noise that Neumann generates by bowing a clothespin attached to the aluminum shelf with a violin bow (Figure 7) reminds her of a signature sound of her fellow ensemble member, the tubist Robin Hayward. The various noisy sounds that Neumann works with-e.g., bowing the edge of the aluminum shelf with a violin bow-also represent a direct material connection, especially to

36 Interview with Andrea Neumann, January 21, 2013. 


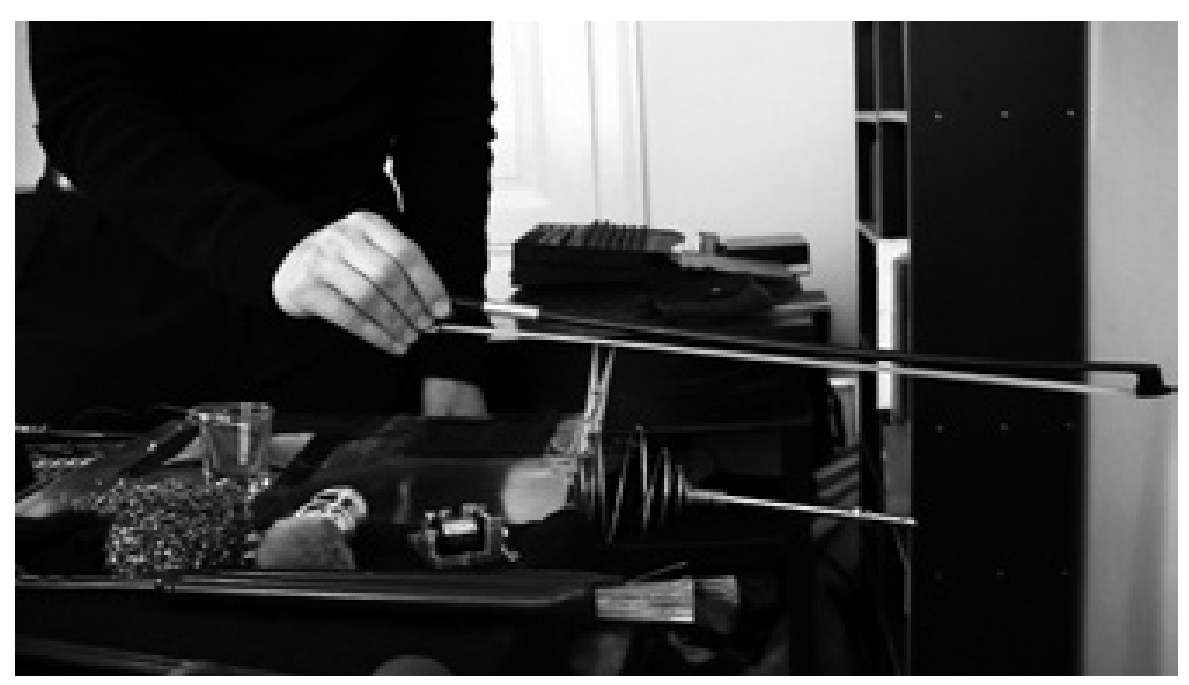

Figure 7: Bowing a clothespin attached to the aluminum shelf (still from video by Matthias Haenisch)

the breath sounds used by Hayward and the trumpeter Axel Dörner, or the static noise of the guitar amplifier employed by the guitarist and electronic musician Annette Krebs.

Neumann's instrumentarium is a materialization of her praxis: the continuous interaction with sounding objects and preparations, the emergence of playing techniques, and the exchange, appropriation, and transformation of musical material have embedded an aesthetic disposition and artistic preference in the technical configuration of the instrumentarium. This process is termed "inscription" in the context of ANT. ${ }^{37}$ Such "scripts" fixed in artifacts are materializations of implicit knowledge that is drawn from the relevant contemporary practice. Likewise they can accommodate spaces for potential further use, implicit visions of future praxis. Through continual interaction and mutual transformation of body and artifacts, the

37 Madeleine Akrich, "The De-Scription of Technical Objects," in Shaping Technology, Building Society: Studies in Sociotechnical Change, ed. Wiebe E. Bijker and John Law (Cambridge: MIT Press, 1992), 20524. 
instrumentarium becomes a "materially stabilized choreography of body postures and movement." 38 The material inscription of the artifact takes on a central role in the performative (re)production of the performer and is an active part of her performance persona because "people are who they are because they are a patterned network of heterogeneous materials." 39

Moreover, instruments—-like all technology—are "society made durable." They stabilize the aesthetic and social relationships between musicians in that they preserve collective memories of experiences and keep them available for upgrades and advancements. The materialization of praxis in an instrument in no way entails limiting the performer to strict norms or rules based on technical requirements, for example to an exclusively "reductive" attitude to playing. With this in mind ANT emphasizes the flexibility, fluidity, and permanent malleability of technology. As such, Neumann's obvious preference for separately excited or self-excited oscillating processes opens up the possibility of activating several objects simultaneously, which can lead to multilayered and polyphonic structures beyond "reductive" procedures. Recordings with Krebs from 2000 document the wide range of the instrument's potential and showcase Neumann's sounds in complex and lively interactions. ${ }^{41}$ Both the "return to rhythmic and gestural patterns, ... comprehensible formal structures, linear progression" ${ }^{42}$ that Polaschegg observes in Neumann's modus operandi as well as her growing interest in sometimes massive electroacoustic feedback drones are also effects of a continued investigation of material affordances beyond reductive strategies. Only Neumann's recent increasing

38 Schmidt, Soziologie der Praktiken, 154.

39 John Law, "Notes on the Theory of the Actor-Network: Ordering, Strategy and Heterogenity," Systems Practice 5/4 (1992): 383.

40 Bruno Latour, "Technology is society made durable," in A Society of Monsters: Essays on Power, Technology and Domination, ed. John Law (London, New York: Routledge, 1991), 103-31.

41 Annette Krebs and Andrea Neumann, Rotophormen (charzima 009, 2000).

42 Polaschegg, "Reflexive Improvisation,” 229. 
interest in the reintegration of tonal material really pushes the boundaries of the instrument and could, as she indicated in another interview, necessitate extensive modification or expansion of the Inside Piano in order to fit the instrument with a rudimentary keyboard. ${ }^{43}$ Thus the performer-instrument network is not in a state of increasing fossilization but rather in a process of continuous performative reconfiguration.

The agency of artifacts is by no means simply restricted to the configuration of the instrumentarium and its playing techniques, but is also seen in the playing process of improvisation. The sounds that Neumann has worked out are explored to the finest detail of texture, and the behavior of objects and preparations are familiar from targeted practice and repeated performance. Having said that, not only the search for but also the reproduction of noises and sounds is influenced by many unpredictable factors. Occasionally one has to surrender oneself to an

anarchic or chaotic process, whose results resist being fixed in any sort of notation: for example I take a small pickup and run it over a string. Which part of the pickup first comes into contact with the string? And when I move it, what part then in next touches the string? These small alterations generate a vast spectrum of pitches and sounds. The musical material is recalcitrant to reproduction. ${ }^{44}$

Often it is the material properties of an object (i.e., a steel wool ball, Figure 9) that are unsuitable for achieving a precise sound reproduction, or the fragility of a combination of objects (i.e., a vibrating bar magnet that is placed on a piano string or on a guitar pickup) that refuse to let themselves be subject to an exact way of playing.

43 Interview with Andrea Neumann, January 21, 2013.

44 Gisela Nauck, "Alte Fragen neu: Form und Inhalt. Ein Gespräch von Gisela Nauck mit Annette Krebs, Andrea Neumann, Serge Baghdassarians, Burkhard Beins und Axel Dörner," positionen. Texte zur aktuellen Musik 62 (2005): 13. 


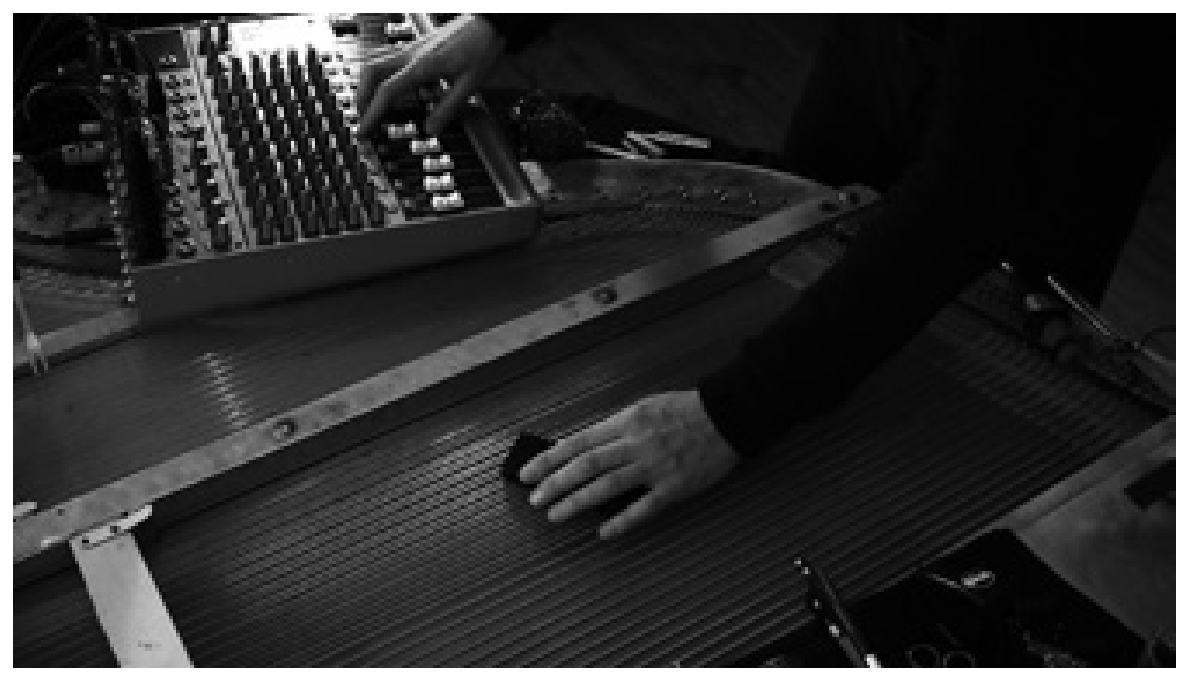

Figure 8: Scratching strings with a guitar pickup (still from video by Matthias Haenisch)

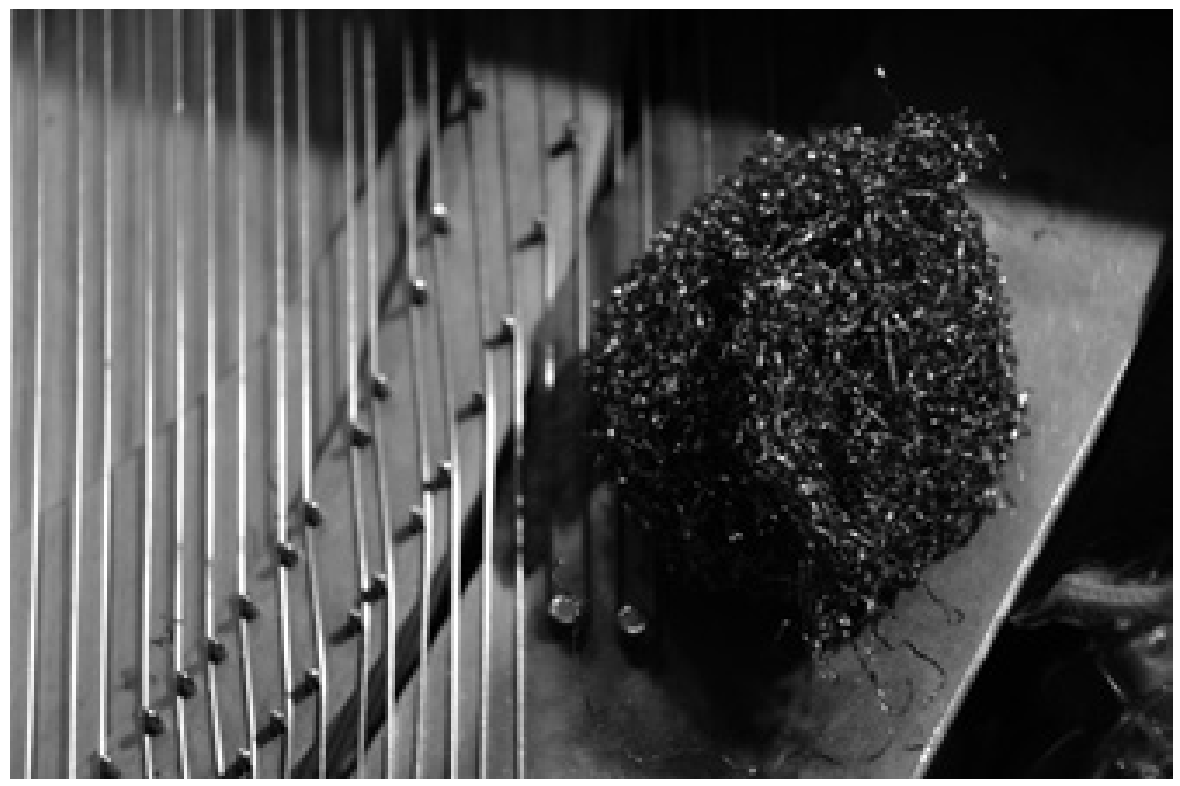

Figure 9: Steel wool ball (photo by Manuela Stark) 
This resistance of the artifacts is a fundamental aspect of their efficacy as agents. In this context the instrument acts as a counterpart "that cannot be mastered, that has its own momentum" and that can behave out of line with expectations: "if I do something three times in a row, it sounds different every time. It is extremely difficult to predict a result and to create structures where I know exactly when something will happen." ${ }^{45}$ From a socio-technological perspective, such resistance and indeterminacy are clear indications for the agency of artifacts, as an interactive communicative relationship between human and technology comes into being when an artifact behaves contrary to expectations, that is, when it acts contingently. ${ }^{46} \mathrm{It}$ is in this sense that Latour designates actors

as obstacles, scandals, as what suspends mastery, as what gets in the way of domination, as what interrupts the closure and the composition of the collective. To put it crudely, human and nonhuman actors appear first of all as troublemakers. The notion of recalcitrance offers the most appropriate approach to defining their action. ${ }^{47}$

However, the contingency and resistance of the material is not a matter of insufficient playing technique that could or should be completely mastered with practice and increased control. Rather, it plays a fundamental aesthetic role. Repetition creates deviations that can be taken as impulses and triggers for the performance. Thus the reproduction of sounds becomes a performative production of differences that are capable of decisively altering the course of an improvisation. Accordingly the material resistance and indeterminacy of

45 Interview with Andrea Neumann, January 21, 2013.

46 Werner Rammert, "Technik in Aktion: Verteiltes Handeln in soziotechnischen Konstellationen," in Autonome Mascbinen, ed. Thomas Christaller and Josef Wehner (Wiesbaden: Westd. Verlag, 2003), 289-315.

47 Bruno Latour, Politics of Nature (Cambridge: Harvard University Press, 2004), 81. 
the instrument demands a specific type of listening: "because the material is recalcitrant, I have to always stay curious. If it always happened as I expected it, I wouldn't need to listen so carefully anymore." 48 A consistently high level of attention and sharp motor reflexes in response to small and large deviations are essential so that Neumann can keep pace with the effects that these deviations can have on the course of the improvisation by being prepared to make manual adjustment at any moment. ${ }^{49}$ The often mentioned appreciation that many improvisers have for productive disorientation, happy accidents, and unpredictability is inscribed into the materiality of Neumann's instrumentarium. ${ }^{50}$ Because of their material stubbornness, the artifacts call for the presence of the performer, hinder routinization, and act as agents in a collective creativity.

It is precisely the indeterminacies that lead me down unexpected twists and turns. It can be a pulsation in feedback that I hadn't intended, which I then might try to amplify or react to with another sound, and this then takes me down a new path. And sometimes the instrument does something that is not only unexpected but much better than what I actually wanted ${ }^{51}$

The repurposing of things and artifacts is an encounter with their alterity. It facilitates the productive inclusion of the impetuous resistance of the object. It recognizes in technology a force that transforms the human element and gives the improviser cause to ask, "are we performing the technology or is

48 Interview with Andrea Neumann, May 25, 2013.

49 Cf. Keep, "Instrumentalizing," 118: "During the process of instrumentalizing the performer needs a ... type of listening that is responsive of real-time activity."

50 Annette Krebs et al., "Zum kreativen Potential des Fehlers: Statements von KomponistInnen und MusikerInnen," positionen. Texte zur aktuellen Musik 79 (2009): 32-39.

51 Interview with Andrea Neumann, May 25, 2013. 
it performing us?"52 Apparently the practice of instrumentalizing, which emerged in the course of the expansion of musical material, offers instruments and artifacts recognition as material actors in the improvisation. However, the point is not to equate human and non-human actors, nor to detract from human artistic achievement and responsibility, but rather to integrate the influential presence and meaning of artifacts and objects into our notion of artistic ingenuity. Above all it is a part of Neumann's artistic impetus (as well as that of many other musicians) to value and expose the potency and obstinacy of objects in a creative way. A consideration of the agency and performativity of material can already serve in the observation of the reciprocal coupling of human and non-human: in the praxeological classification of the artifact as a physical mediator for transporting implicit knowledge and a collective history of interaction, and moreover in the identification of the program of action and aesthetic principles that are inscribed in the artifact.

By classifying instrumentaria and objects as agents of transformative efficacy and contingently acting participants, it becomes clear, however, that they can effectively influence the course of an improvisation. In this context artifacts act as delegates of a performative aesthetic, whose potential for innovation is not only derived from interaction among humans but also benefits from human-non-human interaction. For the analysis of performances of improvised music this should mean that, alongside corporeality, the materiality of things should also be recognized as an agent of performative practices, and the number of actors to expect and observe should be increased, as

to distribute roles from the outset between the controllable and obedient object on the one hand and the free and rebellious human on the other is to preclude searching for the conditions under which ... one can ... make

52 John Robert Ferguson and Robert van Heumen, "Whistle Pig Saloon: Performing Technologies," Leonardo Music Journal 20 (2010): 12. 
these entities exchange among themselves their formidable capacity to appear on the scene as full-fledged actors. ${ }^{53}$

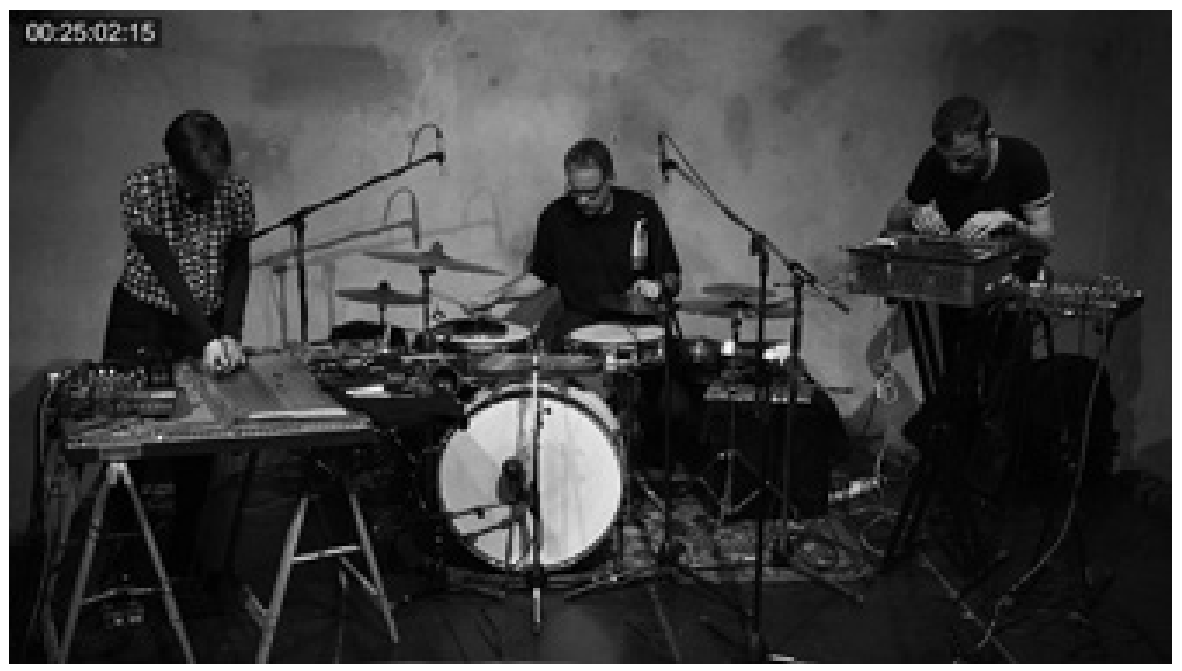

Figure 10: Andrea Neumann, Inside Piano; Burkhard Beins, percussion, objects; Valerio Tricoli, reelto-reel tape recorder. Concert at Ausland, Berlin-Prenzlauer Berg, May 15, 2013 (still from video by Matthias Haenisch and Ronny Zimmermann)

53 Latour, Politics of Nature, 81. 


\section{Franck Bedrossian}

\section{What is noise (music) to you?}

"Noise" is the name that we give to a sound that does not have any $a$ priori musical function and that is, for this reason, identified as nonmusical. From that point of view only, speaking of noise music would be nonsense, as each sound perceived as musical is not a noise anymore.

But if one tries to define the main characteristics of this category of sounds, then two traits clearly emerge:

1. Noises are considered non-musical because their acoustic structure does not refer to-even contradicts-the usual hierarchy between musical parameters in the Western musical tradition, in other words all sounds that do not project pitch as a prominent quality.

2. Sounds that are considered noises are actually produced by sources and devices (nature, computers, urban life, etc.) that are not supposed to integrate into musical discourse because their anecdotal aspector cultural charge (sounds of everyday life, white noises of all kinds, etc.) - is immediately associated with non-musical situations in the mind of a listener.

Then one could say "noise music" is a music in which sonic material is made of complex sounds that deny pitch to be the most prominent dimension, and that despite an extra- or non-musical connotation are given structural functions within a network of musical relationships. 


\section{Why do you make it?}

I do not consider myself a composer of "noise music." However, integrating the acoustic and aesthetic potentialities of all kinds of acoustically complex sounds in my music does represent one of the main stakes of my research.

Knowing that the instrumental world, as it has been conceived within the Western tradition, tends to exclude or hide complex sounds from instrumental possibilities, an approach that includes them and gives them musical functions allows composers to transcend categories, to play with the thresholds of perception, and to modify or even subvert the hierarchies within musical discourse.

Eventually, the integration of different territories of what we call "noise" represents a compositional and aesthetic challenge that might help to create different types of musical pleasure and emotions. 